\title{
4 \\ Qualitative Cranio-Morphology \\ at Man Bac
}

\author{
Yukio Dodo \\ Tohoku University School of Medicine, Japan
}

\begin{abstract}
Cranial nonmetric traits are widely accepted to be effective for reconstructing population histories, not only within limited regions but also globally (Ossenberg, 1986, 1994; Dodo and Ishida, 1990; Dodo and Kawakubo, 2002; Hanihara et al., 2003; Dodo and Sawada, 2010). In this chapter, the occurrence of cranial nonmetric traits is assessed for the Man Bac series, and the origins and affinities of the Man Bac people are discussed in the context of local and regional populations in East and Southeast Asia.
\end{abstract}

\section{MATERIALS AND METHODS}

The presence/absence of 22 nonmetric traits was examined for 33 adult and near-adult crania from the Man Bac site: 4 from the 1999-2001 season, 11 from the 2005 season, and 18 from the 2007 season. The criteria employed here for scoring nonmetric traits are given in Dodo (1974) and Dodo and Ishida (1990). The following 6 traits were used for comparison of the frequencies among cranial samples:

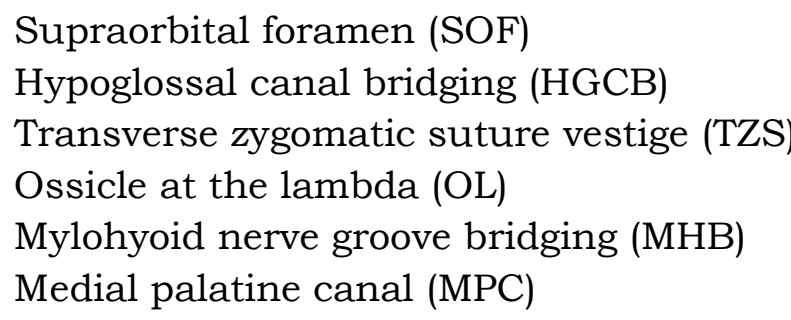

These 6 nonmetric traits are little affected by interobserver error in scoring (Ishida and Dodo, 1990) and have been noted as good measures for population relationships in the Japanese Islands (Dodo and Ishida, 1990). Furthermore, the supraorbital foramen and hypoglossal canal bridging are believed to be highly effective in discriminating amongst major human groupings globally (Dodo, 1986; Dodo and Sawada, 2010).

Table 4.1 provides summary information on the 6 cranial samples compared: Neolithic Weidun and early historic Eastern Zhou/Western Han on the lower reaches of the Yangtze River, Jiangsu, southern China; modern mainland Southeast Asians including inhabitants of Vietnam, Laos, Cambodia, and Thailand; modern southern Chinese derived from south of the Yangtze River; and modern Australian 


\section{Y. DODO}

Aborigines.

Biological distances among the samples were assessed via Smith's Mean Measure of Divergence statistic (MMD) defined as follows:

$$
\operatorname{MMD}=1 / \mathrm{r} \sum\left[\left(\theta_{1}-\theta_{2}\right)^{2}-\left(1 / \mathrm{n}_{1}+1 / \mathrm{n}_{2}\right)\right]
$$

where $r$ is the number of traits; $\theta_{1}$ and $\theta_{2}$ are angular transformations in radian of the trait frequencies $p_{1}$ and $p_{2}$ in two samples, obtained by the formula $\theta=\operatorname{arcsine}$ $(1-2 p)$; and $n_{1}$ and $n_{2}$ are the numbers of observations in the two samples (Sjøvold, 1973).

Two statistical methods for graphic representation were applied to the matrix of MMDs to depict the relationships of the samples. One is group average clustering analysis and the other is the multi-dimensional scaling method. The procedures of these statistical analyses were kindly carried out by Professor H. Matsumura of Sapporo Medical University, using data analysis software "STATISTICA Version 06J" produced by StatSoft Japan Inc., Tokyo.

Table 4.1 Cranial samples used for nonmetric analyses.

\begin{tabular}{|c|c|c|c|}
\hline Sample name & Provenance & Period & Reference \\
\hline Man Bac & Ninh Binh, northern Vietnam & $\begin{array}{l}\text { neolithic } \\
(3,300-3,500 \text { uncal.BP })\end{array}$ & Present study \\
\hline Weidun & $\begin{array}{l}\text { Lower reaches of the Yangtze River, } \\
\text { Jiangsu, China }\end{array}$ & $\begin{array}{l}\text { Neolithic } \\
(6,000-5,000 \mathrm{BP})\end{array}$ & Wakebe, 2002 \\
\hline $\begin{array}{l}\text { Zhou/Han } \\
\text { (Eastern Zhou-Western Han) }\end{array}$ & $\begin{array}{l}\text { Lower reaches of the Yangtze River, } \\
\text { Jiangsu, China }\end{array}$ & $\begin{array}{l}\text { Early Historic } \\
(2,800-2,000 \mathrm{BP})\end{array}$ & Wakebe, 2002 \\
\hline $\begin{array}{l}\text { SE-Asia } \\
\text { (Mainland Southeast Asians) }\end{array}$ & $\begin{array}{l}\text { Vietnam, Laos, Cambodia, } \\
\text { and Thailand }\end{array}$ & Modern & $\begin{array}{l}\text { Hanihara and Ishida, } \\
2001 \mathrm{a}, \mathrm{b}, \mathrm{c}, \mathrm{d}, \mathrm{e}\end{array}$ \\
\hline $\begin{array}{l}\text { S China } \\
\text { (Southern Chinese) }\end{array}$ & South of the Yangtze River, China & Modern & $\begin{array}{l}\text { Hanihara and Ishida, } \\
2001 \mathrm{a}, \mathrm{b}, \mathrm{c}, \mathrm{d}, \mathrm{e}\end{array}$ \\
\hline $\begin{array}{l}\text { Australia } \\
\text { (Australian Aborigines) } \\
\end{array}$ & $\begin{array}{l}\text { New South Wales, Queensland, } \\
\text { and Victoria }\end{array}$ & Modern & $\begin{array}{l}\text { Hanihara and Ishida, } \\
\text { 2001a,b,c,d,e }\end{array}$ \\
\hline
\end{tabular}

Table 4.2 Comparison of side-incidences of 6 cranial nonmetric traits.

\begin{tabular}{|c|c|c|c|c|c|c|}
\hline \multirow[b]{2}{*}{ Trait } & \multicolumn{2}{|c|}{ Man Bac } & \multicolumn{2}{|c|}{ Weidun } & \multicolumn{2}{|c|}{ Zhou/Han } \\
\hline & $z$ & $p$ & $\mathrm{n}$ & $p$ & $\mathrm{n}$ & $p$ \\
\hline $1 \mathrm{SOF}$ & 57 & 0.439 & 69 & 0.406 & 52 & 0.519 \\
\hline 2 HGCB & 32 & 0.156 & 45 & 0.044 & 44 & 0.136 \\
\hline 3 TZS & 39 & 0.026 & 37 & 0.081 & 42 & $0.006^{*}$ \\
\hline $4 \mathrm{OL}$ & 24 & $0.010^{*}$ & 22 & 0.045 & 23 & 0.217 \\
\hline $5 \mathrm{MHB}$ & 57 & 0.070 & 81 & 0.099 & 44 & 0.023 \\
\hline $6 \mathrm{MPC}$ & 50 & 0.020 & 74 & 0.041 & 50 & 0.060 \\
\hline
\end{tabular}

\section{RESULTS}

The presence/absence of the 22 nonmetric traits in each cranium of the Man Bac series is shown in the Appendix of this chapter. In Table 4.2, sex- and side-pooled incidences of the 6 nonmetric traits are given for the 6 cranial samples, with the zero proportions being replaced by $1 / 4 \mathrm{n}$ as recommended by Bartlett (Snedecor and Cochran, 1980). Although an anthroposcopic impression suggested the mingling of two types of crania in the Man Bac series (see Chapter 3), i.e., a gracile one and a 
robust one, no such distinction was noticed in the patterning of cranial nonmetric traits. For this reason the Man Bac individuals were treated here as a single

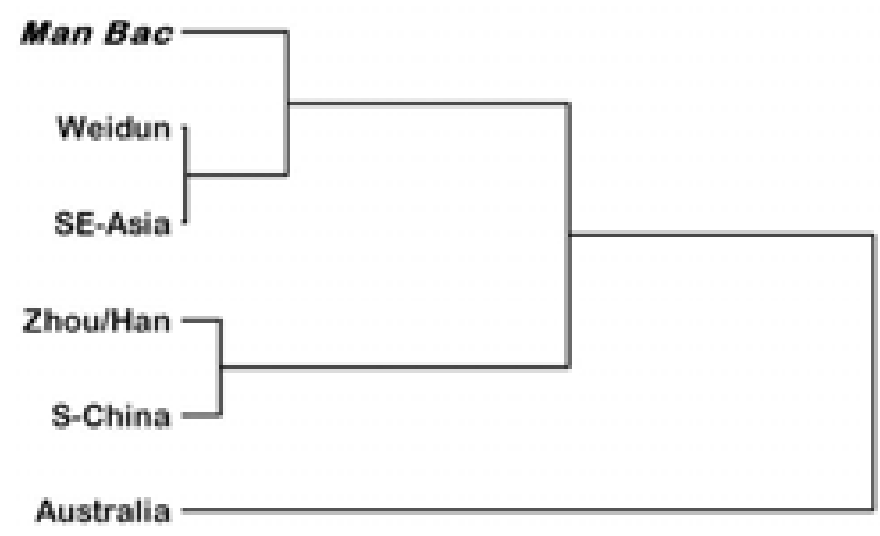

Figure 4.1 Dendrogram of a cluster analysis applied to the MMDs among the samples from mainland Southeast Asia, southern China, and Australia.

Table 4.3 MMDs among the 6 cranial samples compared.

\begin{tabular}{lcccccc}
\hline & Man Bac & Weidun & Zhou/Han & SE-Asia & S China & Australia \\
\hline Man Bac & & 0.0016 & 0.0735 & 0.0270 & 0.0959 & 0.1068 \\
Weidun & 0.0016 & & 0.0778 & 0.0005 & 0.0359 & 0.0652 \\
Zhou/Han & 0.0735 & 0.0778 & & 0.0233 & 0.0052 & 0.1476 \\
SE-Asia & 0.0270 & 0.0005 & 0.0233 & & 0.0084 & 0.0614 \\
S China & 0.0959 & 0.0359 & 0.0052 & 0.0084 & & 0.0880 \\
Australia & 0.1068 & 0.0652 & 0.1476 & 0.0614 & 0.0880 & \\
\hline
\end{tabular}

population sample. Table 4.3 gives MMDs based on the frequencies of the 6 nonmetric traits among the 6 cranial samples compared.

The Man Bac cranial series (3800-3500 years BP) was compared with that of the Neolithic Weidun site (6,000-5,000 years BP) and that of the early historic Eastern Zhou/Western Han (2,800-2,000 years BP) in the Yangtze Basin, southern China. Moreover, comparisons were made with modern cranial samples from mainland Southeast Asia and southern China. Australian aboriginal crania were also used for comparison.

In the MMD matrix of Table 4.3, the closest sample to the Man Bac population is the Neolithic Weidun series from in the Yangtze Basin, and the next closest are modern mainland Southeast Asians. The Australian aboriginal population is the furthest away, and the samples of Eastern Zhou/Western Han and southern Chinese are in-between.

A dendrogram of cluster analysis and a two-dimensional display of multidimensional scaling are depicted in Figure 4.1 and Figure 4.2, respectively. Both figures show a relatively tight cluster of Man Bac, Weidun, and mainland Southeast Asians. Another cluster is seen between the Eastern Zhou/Western Han and southern Chinese. 


\section{DISCUSSION}

It was noticed that there is a close relationship between Man Bac and the Weidun sample, and that these two series are also close to the crania of mainland Southeast Asians (Table 4.3, Figures 4.1 and 4.2). The cranial and dental metric study of the Man Bac specimens from the 1999-2001 and 2004-2005

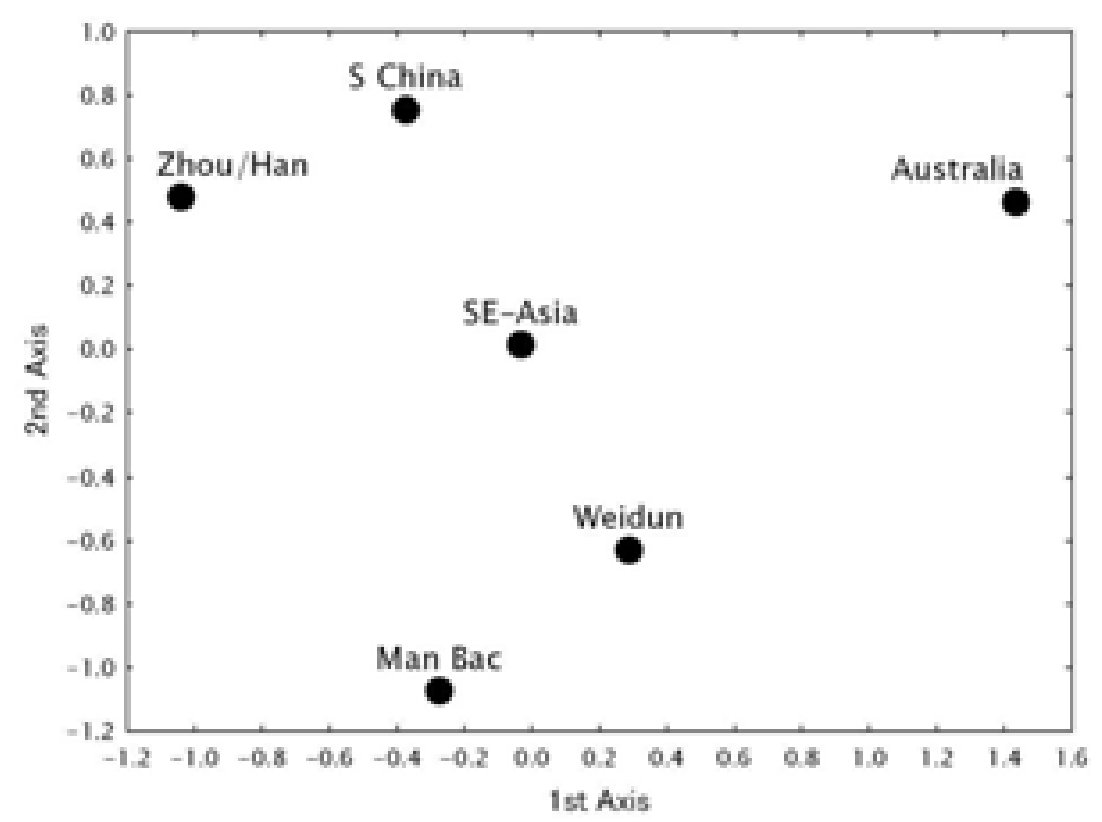

Figure 4.2 Two-dimensional display of the multidimensional scaling method applied to the MMDs among the samples from mainland Southeast Asia, southern China and Australia.

seasons revealed that the Man Bac sample is grouped with the early Metal Age to modern East/Southeast Asian and the Neolithic Weidun people (Matsumura et al., 2008a). Taking into account the findings of the cranial nonmetric and cranial/dental metric analyses, it can be postulated that the inhabitants of Man Bac from northern Vietnam were closely related to the Neolithic Weidun people, essentially a rice-farming culture on the lower reaches of the Yangtze River, and the following schema of population history can be outlined: Neolithic Weidun $\rightarrow$ neolithic Man Bac $\rightarrow$ early Iron Age Dong Son $\rightarrow$ modern mainland Southeast Asians.

Recent studies have disclosed that the late Pleistocene and early Holocene human remains from Southeast Asia, such as Gua Gunung Runtuh in Peninsular Malaysia and Mai Da Nuoc, Mai Da Dieu, and Hang Cho in northern Vietnam, exhibit osteological characteristics shared with 'Australo-Melanesians' (Matsumura and Zuraina, 1999; Cuong, 1986; Matsumura et al., 2008b). These researchers have argued that Southeast Asia was first occupied by an indigenous population, sometimes referred to as 'Australo-Melanesian', before immigrants from East Asia dispersed widely into this region (Matsumura and Hudson, 2005; Matsumura et al., 2008a).

The results of the present nonmetric analysis, however, revealed little affiliation between the Man Bac inhabitants and the Australian aboriginal sample, as shown in Table 4.3 and Figures 4.1-4.2. Most likely, the prototype population ancestral to modern mainland Southeast Asians, which would appear to be quite different to 'Australo-Melanesians', was already established by the time of the neolithic in 
northern Vietnam.

In order to reconstruct the population history in Vietnam more systematically, samples of the Early to Middle Holocene Hoabinhian, Bacsonian, and Da But cultures, as well as the Early Metal Age Dong Son culture, need to be investigated in terms of cranial nonmetric variation.

\section{SUMMARY}

The presence/absence of 22 nonmetric traits was examined for 33 adult and near-adult crania from the Man Bac site. The frequencies of the 6 traits, which are little affected by interobserver error in scoring, were used for comparison among the 6 neolithic to modern cranial samples from mainland Southeast Asia, southern China, and Australia. Biological distances assessed by Smith's Mean Measure of Divergence indicated that the Man Bac series is closest to Neolithic Weidun in the Yangtze Basin in southern China, and next closest to modern mainland Southeast Asians. From these findings, it was inferred that the Man Bac people, genetically influenced by those represented by the Neolithic Weidun rice-farming people in the Yangtze Basin, are a prototype population ancestral to modern mainland Southeast Asians.

\section{ACKNOWLEDGMENTS}

I express my sincere gratitude to Professor T. Hanihara of Kitasato University School of Medicine for providing me with cranial nonmetric raw data of the Southeast Asian, southern Chinese, and Australian samples. The present study was supported by Grant-in-Aid in 2003-2005 (No. 15405018) and 2008-2009 (No. 20370096) from the Japan Society for the Promotion of Science.

\section{LITERATURE CITED}

Cuong NL. 1986. Two early Hoabinhian crania from Thanh Hoa province, Vietnam. Zeitschrift für Morphologie und Anthropologie 77: 11-17. Dodo Y. 1974. Nonmetrical cranial traits in the Hokkaido Ainu and the northern Japanese of recent times. J Anthropol Soc Nippon 82: 31-51.

Dodo Y. 1986. Supraorbital foramen and hypoglossal canal bridging: the two most suggestive nonmetric traits in discriminating major racial groupings of man. $\mathrm{J}$ Anthropol Soc Nippon 95: 19-35.

Dodo Y, Ishida H. 1990. Population history of Japan as viewed from cranial nonmetric variation. J Anthropol Soc Nippon 98: 269-287.

Dodo Y, Kawakubo Y. 2002. Cranial affinities of the Epi-Jomon inhabitants in Hokkaido, Japan. Anthropol Sci 110: 1-32.

Dodo Y, Sawada J. 2010. Supraorbital foramen and hypoglossal canal bridging revisited: their worldwide frequency distribution. Anthropol Sci 118 (in press)

Hanihara T, Ishida H. 2001a. Os incae: variation in frequency in major human population groups. J Anat 198: 137-152.

Hanihara T, Ishida H. 2001b. Frequency variations of discrete cranial traits in major human populations. I. Supernumerary ossicle variations. J Anat 198: 689-706.

Hanihara T, Ishida H. 2001c. Frequency variations of discrete cranial traits in major human populations. II. Hypostotic variations. J Anat 198: 707-725. 


\section{Y. DODO}

Hanihara T, Ishida H. 2001d. Frequency variations of discrete cranial traits in major human populations. III. Hyperostotic variations. J Anat 199: 251-272.

Hanihara T, Ishida H. 2001e. Frequency variations of discrete cranial traits in major human populations. IV. Vessel and nerve related variations. J Anat 199: 273-287.

Hanihara T, Ishida H, Dodo Y. 2003. Characterization of biological diversity through analysis of discrete cranial traits. Am J Phys Anthropol 121: 241-251.

Ishida H, Dodo Y. 1990. Interobserver error in scoring nonmetric cranial traits. J Anthropol Soc Nippon 98: 403-409.

Matsumura H, Zuraina M. 1999. Metric analyses of an early Holocene human skeleton from Gua Gunung Runtuh, Malaysia. Am J Phys Anthropol 109: 327-340.

Matsumura H, Hudson MJ. 2005. Dental perspective on the population history of Southeast Asia. Am J Phys Anthropol 127: 182-209.

Matsumura H, Oxenham MF, Dodo Y, Domett K, Thuy NK, Cuong NL, Dung NK, Huffer D, Yamagata M. 2008a. Morphometric affinity of the late Neolithic human remains from Man Bac, Ninh Binh Province, Vietnam: key skeletons with which to debate the two layer' hypothesis. Anthropol Sci 116: 135-148.

Matsumura H, Yoneda M, Dodo Y, Oxenham MF, Cuong NL, Thuy NK, Dung LM, Long VT, Yamagata M, Sawada J, Shinoda K, Takigawa W. 2008b. Terminal Pleistocene human skeleton from Hang Cho Cave, northern Vietnam: implications for the biological affinities of Hoabinhian people. Anthropol Sci 116: 201-217.

Ossenberg NS. 1986. Isolate conservatism and hybridization in the population history of Japan: the evidence of nonmetric cranial traits. In: Akazawa T, Aikens CM, editors. Prehistoric Hunter-Gatherers in Japan. Univ Mus Univ Tokyo Bulletin 27: 199-215.

Ossenberg NS. 1994. Origins and affinities of the native people of northwestern North America: the evidence of cranial nonmetric traits. In: Bonichsen R, Steele DG, editors. Method and Theory for Investigating the Peopling of America. Corvallis, OR: Center for the First Americans, Oregon State University. p 79-115.

Sjøvold T. 1973. The occurrence of minor nonmetrical variants in the skeleton and their quantitative treatment for population comparisons. Homo: 24: 204-233.

Snedecor GW, Cochran WG. 1980. Statistical Methods. 7th edition. Iowa: Iowa State University Press.

Wakebe T. 2002. Human skeletal remains excavated from Jinagnan area in China as viewed from cranial nonmetric variation. In: Nakahashi T, Li M, editors. Ancient People in The Jiangnan Region, China. Fukuoka; Kyushu University Press. p 35-49. 


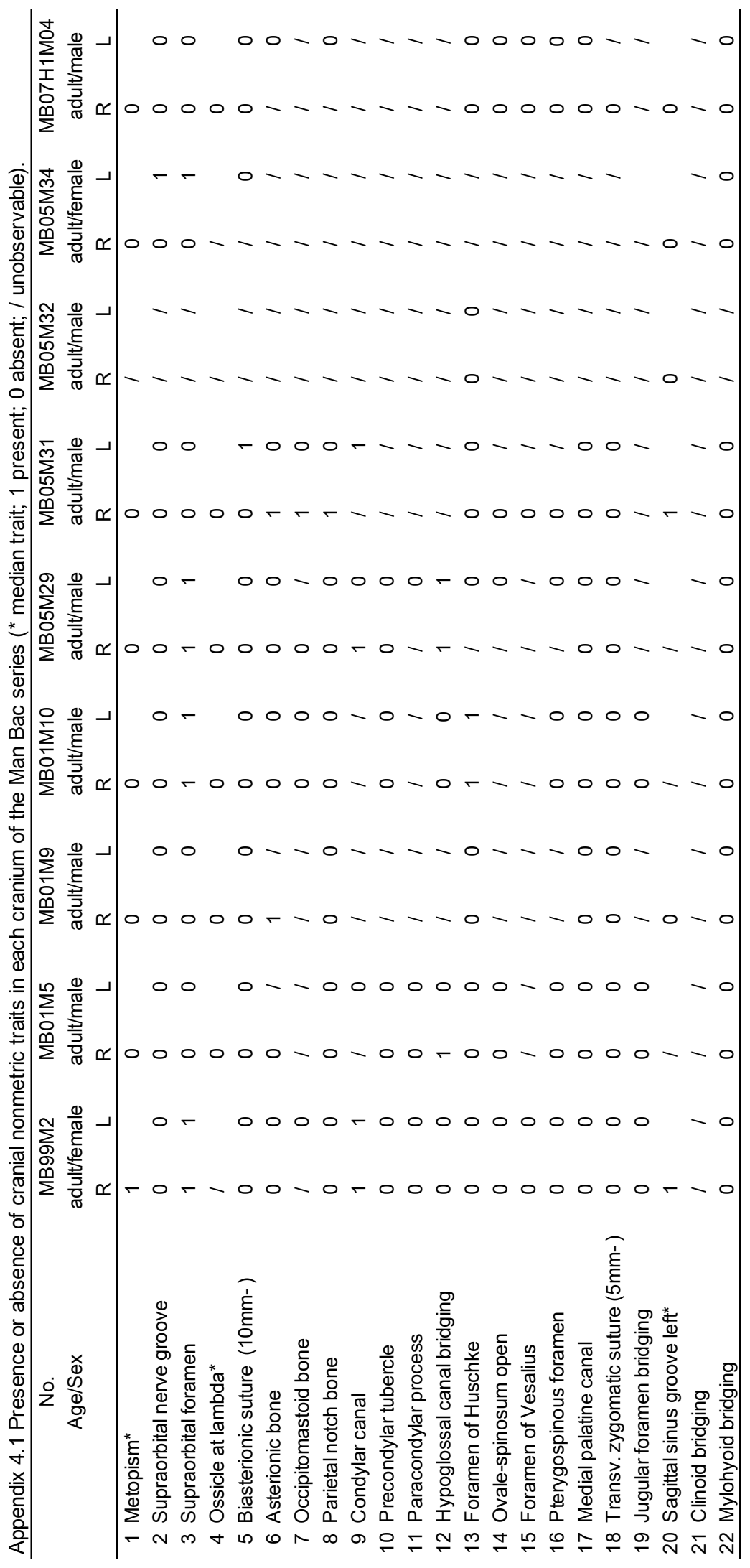




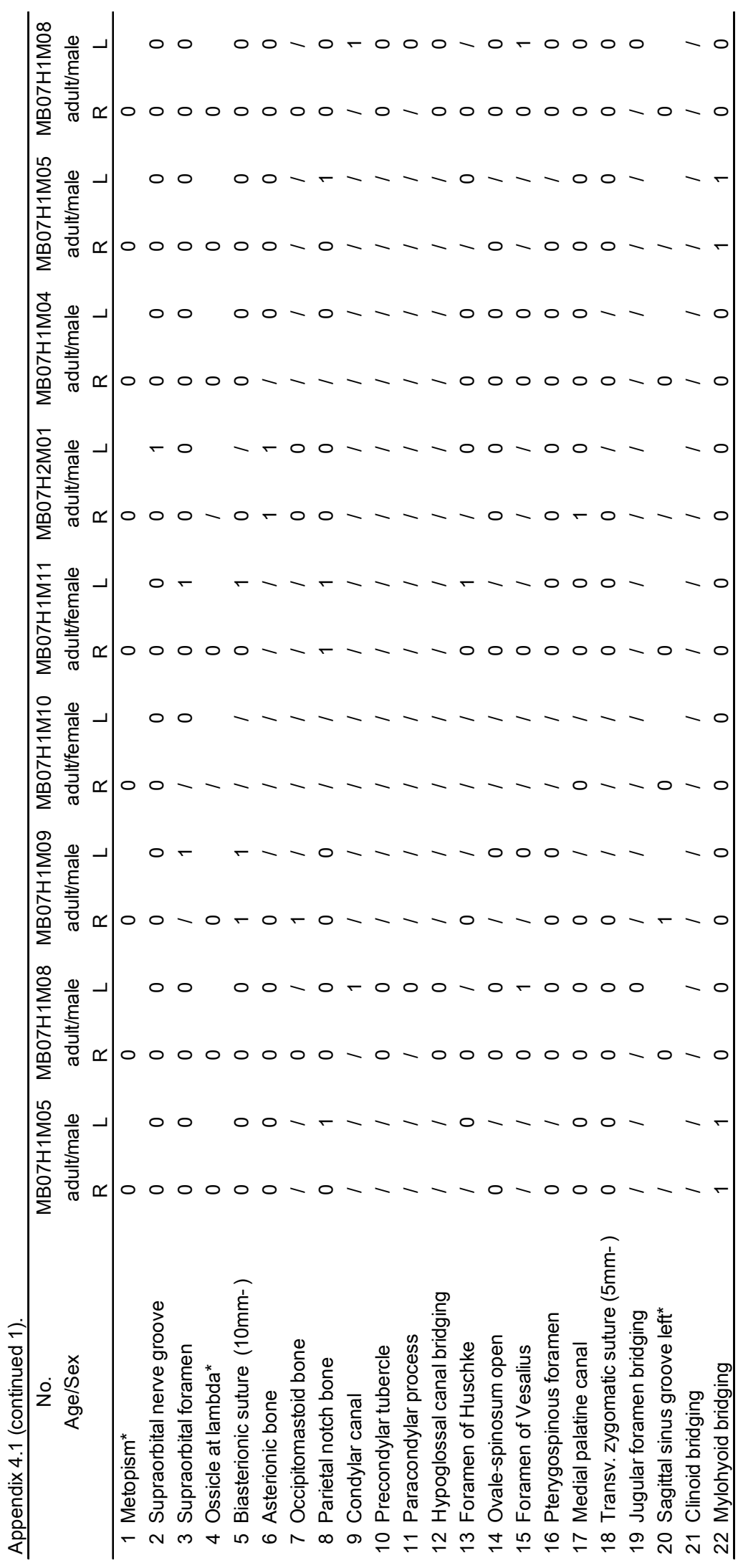




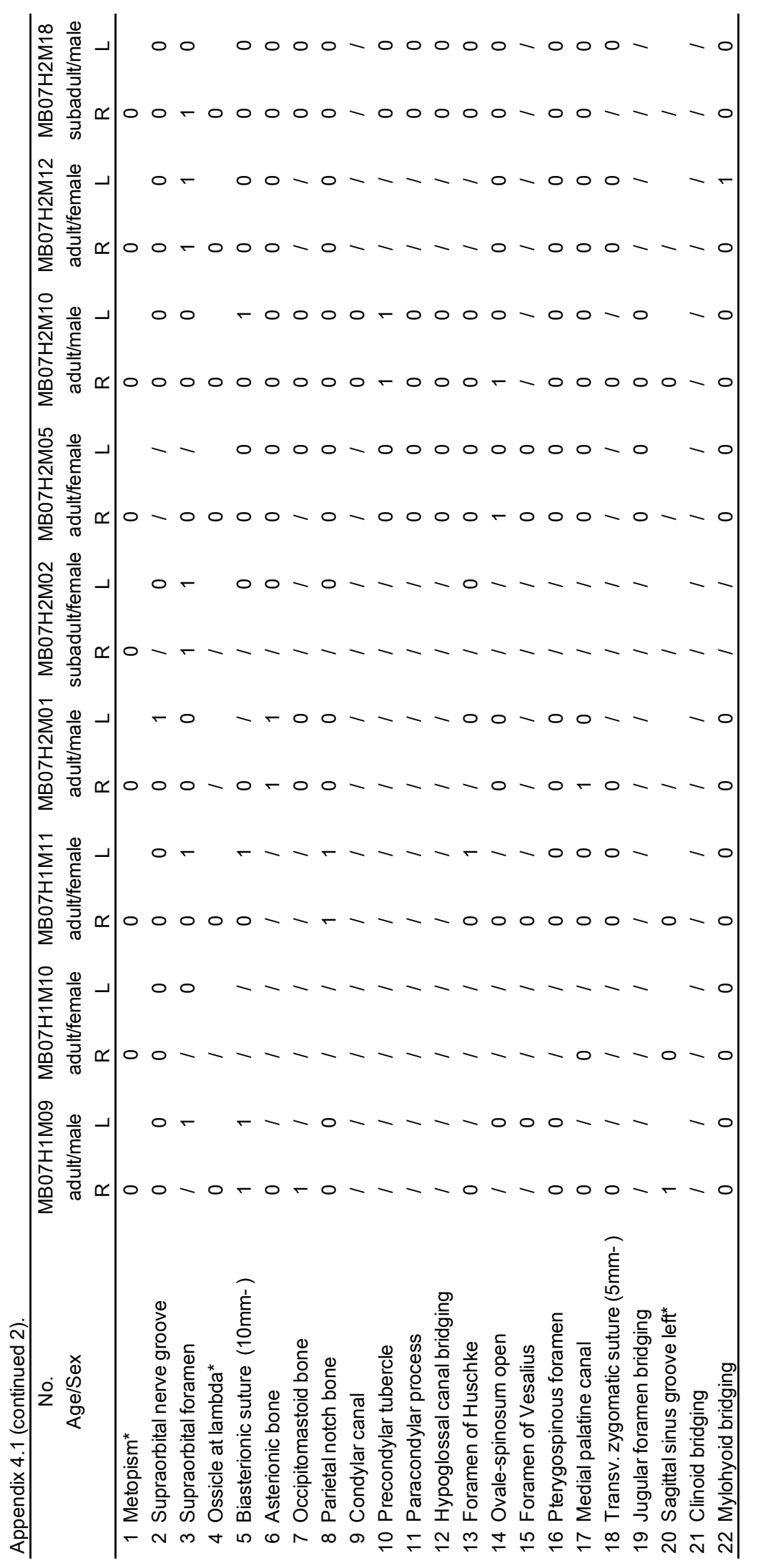




\section{Y. DODO}

Appendix 4.1 (continued 3).

\begin{tabular}{|c|c|c|c|c|c|c|c|c|c|c|c|c|}
\hline \multirow[t]{2}{*}{$\begin{array}{c}\text { No. } \\
\text { Age/Sex }\end{array}$} & \multicolumn{2}{|c|}{$\begin{array}{l}\text { MB07H2M19 } \\
\text { adult/male }\end{array}$} & \multicolumn{2}{|c|}{$\begin{array}{l}\text { MB07H2M22 } \\
\text { adult/female }\end{array}$} & \multicolumn{2}{|c|}{$\begin{array}{l}\text { MB07H2M24 } \\
\text { adult/female }\end{array}$} & \multicolumn{2}{|c|}{$\begin{array}{l}\text { MB07H2M27 } \\
\text { adult/male }\end{array}$} & \multicolumn{2}{|c|}{$\begin{array}{l}\text { MB07H2M30 } \\
\text { adult/male }\end{array}$} & \multicolumn{2}{|c|}{$\begin{array}{c}\text { MB07H2M32 } \\
\text { adult/male }\end{array}$} \\
\hline & $\mathrm{R}$ & $\mathrm{L}$ & $\mathrm{R}$ & $\mathrm{L}$ & $\mathrm{R}$ & $\mathrm{L}$ & $\mathrm{R}$ & L & $\mathrm{R}$ & $\mathrm{L}$ & $\mathrm{R}$ & $\mathrm{L}$ \\
\hline 1 Metopism* & 1 & & 0 & & 0 & & 0 & & 0 & & 0 & \\
\hline 2 Supraorbital nerve groove & I & I & 1 & 1 & 0 & 0 & 0 & 0 & 0 & 0 & 0 & 0 \\
\hline 3 Supraorbital foramen & l & l & 0 & 0 & 0 & 0 & 1 & 1 & 0 & 1 & 1 & 1 \\
\hline 4 Ossicle at lambda* & l & & 0 & & 0 & & 0 & & 0 & & 0 & \\
\hline 5 Biasterionic suture $(10 \mathrm{~mm}-)$ & l & l & 0 & 0 & 0 & 0 & 0 & 0 & 0 & 0 & 0 & l \\
\hline 6 Asterionic bone & l & 1 & 0 & 0 & 1 & 0 & 0 & 0 & 1 & l & 0 & 0 \\
\hline 7 Occipitomastoid bone & I & l & 0 & 0 & I & 0 & 0 & 0 & 1 & I & 1 & 0 \\
\hline 8 Parietal notch bone & 1 & 1 & 0 & 0 & 0 & 0 & 0 & 0 & 0 & 0 & 0 & 0 \\
\hline 9 Condylar canal & l & l & l & I & I & l & 1 & I & 1 & l & 1 & I \\
\hline 10 Precondylar tubercle & l & l & 0 & 0 & 1 & l & 0 & 0 & l & 0 & 0 & 0 \\
\hline 11 Paracondylar process & l & l & 0 & I & I & l & 1 & I & 1 & I & l & I \\
\hline 12 Hypoglossal canal bridging & l & 1 & 0 & 1 & I & I & 0 & 0 & 0 & 0 & 1 & 0 \\
\hline 13 Foramen of Huschke & l & l & 0 & 0 & 0 & 0 & 0 & 0 & 0 & 0 & 1 & I \\
\hline 14 Ovale-spinosum open & l & l & 0 & 0 & I & l & 1 & 0 & l & 0 & 0 & l \\
\hline 15 Foramen of Vesalius & I & I & l & I & I & l & 1 & I & I & l & I & I \\
\hline 16 Pterygospinous foramen & 1 & 1 & 0 & 0 & 1 & l & 0 & 0 & l & 0 & 0 & l \\
\hline 17 Medial palatine canal & l & l & 0 & 0 & 0 & l & 0 & 0 & 0 & 0 & l & 0 \\
\hline 18 Transv. zygomatic suture (5mm- ) & l & I & 0 & 0 & 1 & l & 0 & 0 & 0 & l & 0 & 0 \\
\hline 19 Jugular foramen bridging & l & l & 0 & 0 & I & l & l & 0 & 1 & I & l & I \\
\hline 20 Sagittal sinus groove left & l & & l & & 0 & & 1 & & 0 & & 0 & \\
\hline 21 Clinoid bridging & I & I & I & I & I & l & 1 & I & I & I & I & I \\
\hline 22 Mylohyoid bridging & 0 & 0 & 0 & 0 & 1 & 1 & 0 & 1 & 1 & 0 & 0 & 0 \\
\hline
\end{tabular}

